\begin{tabular}{|l|l|l||}
\hline \multicolumn{2}{|c|}{ PublisherInfo } \\
\hline \hline PublisherName & $:$ & BioMed Central \\
\hline \hline PublisherLocation & $:$ & London \\
\hline \hline PublisherImprintName & $:$ & BioMed Central \\
\hline \hline
\end{tabular}

\title{
Mivazerol may reduce cardiac risk in vascular surgical patients
}

\begin{tabular}{|l|l|l||}
\hline \multicolumn{2}{|c||}{ ArticleInfo } \\
\hline \hline ArticleID & $:$ & 4157 \\
\hline \hline ArticleDOI & $:$ & $10.1186 /$ ccf-1999-2121 \\
\hline \hline ArticleCitationID & $:$ & 2121 \\
\hline \hline ArticleSequenceNumber & $:$ & 16 \\
\hline \hline ArticleCategory & $:$ & Paper Report \\
\hline \hline ArticleFirstPage & $:$ & 1 \\
\hline \hline ArticleLastPage & $:$ & 4 \\
\hline \hline & $:$ & RegistrationDate : 1999-10-27 \\
ArticleHistory & $:$ & OnlineDate $\quad$ 1999-10-27 \\
\hline \hline ArticleCopyright & $:$ & Current Science Ltd1999 \\
\hline \hline ArticleGrants & $:$ & \\
\hline \hline ArticleContext & $:$ & 1305422 \\
\hline \hline
\end{tabular}




\section{Keywords}

Alpha2-adrenergic agonists, cardiac death, general and vascular surgery, myocardial infarction

\section{Comments}

This paper is interesting in that it demonstrates the difficulties in showing a change in outcome related to perioperative management. The trial took 2.5 years to recruit patients from 61 centres and still has the end result that a second study is required to follow up its findings! This study, taken along with the other evidence available, suggests a role for therapies that modulate the catecholamine response to surgery and anaesthesia. The trial went to great efforts in its definitions and analysis of data; however, it appears that other perioperative events may have been overlooked. For example, regional anaesthesia was used in $25 \%$ of the patients. Epidural or spinal anaesthesia has profound (and beneficial?) effects on elements of the catecholamine and stress response to surgery, yet was not looked at separately in the analysis. The number of episodes of acute MI in the treatment and control groups amongst vascular patients was similar (four mivazerol and three controls). The excess cardiac death in the control group occurred as a result of pulmonary oedema. This could have been related to perioperative fluid therapy which was not documented. Overall this interesting paper adds weight to the assumption that intraoperative cardiovascular stability is beneficial.

\section{Introduction}

The sympathoadrenal system is activated during surgery and this may lead to haemodynamic, myocardial and metabolic instability. The risk of death for patients with coronary heart disease (CHD) is high (8-19\%) depending on pre-existing CHD. Vascular surgical patients are the group at highest risk. Reduction of the catecholamine response might reduce the risk of cardiac complications in patients at risk. The drug used was mivazerol hydrochloride, which is an alpha2-receptor agonist and modulates sympathetic efferent stimuli from the spinal cord.

\section{Aims}


The European Mivazerol Trial (EMIT) was designed to determine the efficacy and safety of intravenous mivazerol in patients with $\mathrm{CHD}$ and in patients assessed as being at risk for CHD before undergoing non-cardiac surgery.

\section{Methods}

This randomised, double blind, placebo controlled trial was conducted at 61 different European centres between June 1994 and February 1997. [Patients with known (or at high risk) of CHD] were eligible for the study. An intravenous infusion of saline or mivazerol ( $4 \mu \mathrm{g} / \mathrm{kg}$ for $10 \mathrm{~min}$ then $1.5 \mu \mathrm{g} / \mathrm{kg} /$ h) was commenced prior to induction. Primary endpoints were defined as acute myocardial infarction according to a diagnostic protocol, cardiac death (occurring from a primarily cardiac cause). Secondary endpoints were heart failure, arrhythmias and unstable angina. Analysis part way through the trial suggested that the power of the study would be inadequate to find any change in outcome of those at risk of CHD. The protocol was therefore amended and the data dropped from the analysis.

\section{Results}

In total, 1897 patients with previous known CHD were enrolled. In $10.5 \%$ of the treatment group and $9.4 \%$ of the control group the infusion had to be stopped because of adverse events. Mivazerol decreased primary endpoints by $10.4 \%$ and all-causes deaths by $37 \%$; however this was not statistically significant. Bradycardia and the use of atropine (or related drugs) was more common during mivazerol infusion although the use of inotropes was not. The results were not influenced by perioperative beta blockade. In the subgroup of vascular surgery patients there was a significant reduction in overall death or myocardial infarction (relative risk 0.67). All-causes deaths numbered 20 out of 450 in the placebo group and 8 out of 454 in the treatment group. Cardiac deaths were 18 out of 450 and 6 out of 450 . These positive results were restricted to patients undergoing aortic surgery with no differences in infrainguinal surgery. Mean length of intensive therapy unit (ITU) stay was not changed.

\section{Discussion}

The intravenous infusion of mivazerol did not reduce the incidence of MI or death in patients with CHD. In a preplanned subgroup of vascular patients there was a significant reduction in the incidence of cardiac deaths during the operative and immediate postoperative period. This may well be because the factors contributing to peripheral vascular disease are similar to those contributing to CHD and also the nature of aortic surgery in particular leads to fluctuations in intravascular volume, filling pressures and systolic blood pressure. Additionally, myocardial ischaemia and postoperative tachycardia are both risk factors for cardiac morbidity and mortality. The effects of the infusion could be to prevent myocardial 
events beyond the infusion period. There was no increase in inotrope requirements in the treatment group, suggesting that the drug did not produce any important hypotensive effects. The results in the vascular subgroup are interesting and support the initial small studies' results. A specifically designed second study is now required.

\section{References}

1. Oliver MF, Goldman L, Julian DG, Holme I: Effect of mivazerol on perioperative cardiac complications during non-cardiac surgery in patients with coronary heart disease (The European Mivazerol Trial). Anesthesiology. 1999, 91: 951-961. 